\title{
Lifecourse Socioeconomic Position and Racial Disparities in BMI Trajectories Among Black and White Women: Exploring Cohort Effects in the Americans' Changing Lives Study
}

\author{
Tabassum Z. Insaf • Benjamin A. Shaw • Recai M. Yucel • \\ Lisa Chasan-Taber • David S. Strogatz
}

Received: 14 March 2014 / Revised: 7 July 2014 / Accepted: 23 July 2014 / Published online: 19 August 2014

(C) W. Montague Cobb-NMA Health Institute 2014

\begin{abstract}
Introduction Few studies have analyzed the cohort effects of lifecourse socioeconomic position (SEP) on racial disparities in body mass index (BMI) trajectories. We assessed the contribution of lifecourse SEP on racial differences in BMI trajectories among two different age cohorts of women.

Methods Four waves of the Americans' Changing Lives study (1986-2002) were used to compute BMI trajectories for 2,194 Black and White women. Multivariable associations of lifecourse SEP variables (father's education, perceived childhood family status, education, income, wealth, and financial security) with wave 1 (W1) BMI and BMI change were assessed using mixed models.

Results Black women had higher W1 BMI than White women (approximately) in both cohorts (women $<40$ years in 1986 $\left(+2.6 \mathrm{~kg} / \mathrm{m}^{2}(95 \% \mathrm{CI}+1.71,+3.53)\right)$ and women $\geq 40$ in 1986 $\left.\left(+2.68 \mathrm{~kg} / \mathrm{m}^{2}(95 \% \mathrm{CI}+2.12,3.24)\right)\right)$; Black women in the younger cohort had a higher change in BMI $\left(+0.73 \mathrm{~kg} / \mathrm{m}^{2} /\right.$ year $(95 \% \mathrm{CI}+0.17,+1.29))$. High education was associated with lower W1 BMI in both cohorts $(-1.34(95 \% \mathrm{CI}-2.53,-0.15)$ and $-1.08 \mathrm{~kg} / \mathrm{m}^{2}(95 \% \mathrm{CI}-0.50,-1.65)$, respectively). Among the younger cohort, high income was associated with lower W1 BMI $\left(-0.78 \mathrm{~kg} / \mathrm{m}^{2} /\right.$ unit log income $(95 \%$ CI $\left.-1.32,-0.25)\right)$ while among the older cohort, high father's education
\end{abstract}

Electronic supplementary material The online version of this article (doi:10.1007/s40615-014-0038-y) contains supplementary material, which is available to authorized users.

T. Z. Insaf $(\bowtie) \cdot$ B. A. Shaw $\cdot$ R. M. Yucel $\cdot$ D. S. Strogatz

School of Public Health, University at Albany, State University of

New York, Rensselaer, NY 12144, USA

e-mail: tabassum.insaf@health.ny.gov

L. Chasan-Taber

University of Massachusetts, Amherst, MA, USA

D. S. Strogatz

Bassett Research Institute, Cooperstown, NY, USA $\left(-0.78 \mathrm{~kg} / \mathrm{m}^{2}(95 \% \mathrm{CI}-0.06,-1.50)\right)$ and higher wealth $\left(-0.26 \mathrm{~kg} / \mathrm{m}^{2}(95 \% \mathrm{CI}-0.43,-0.08)\right)$ were associated with low W1 BMI. Racial disparities in W1 BMI were attenuated by 20-25\% while those for BMI change remained unexplained on adjustment for lifecourse SEP.

Conclusion In this large population-based dataset, results suggest that the contribution of lifecourse SEP to racial disparities in BMI may be established early in adulthood.

Keywords Socioeconomic $\cdot$ Racial disparities · BMI · Multi-level models · Trajectories · Lifecourse effects · Women's health

Race and socioeconomic position (SEP) are important correlates of body mass index (BMI), especially among women [1, 2]. However, racial disparities persist even after controlling for current SEP [3-5]. The cumulative inequality (CI) theory combines the cumulative disadvantage and pathway models of lifecourse SEP theory [6] and posits that early exposures to adverse circumstances predict adulthood disadvantage and amplify differences as people age [7]. However, these disadvantages can be modified by available resources, perceived trajectories, and changes in behavior. Differences in childhood SEP and the resulting lifecourse socioeconomic disadvantage may explain some of the persistent racial disparities in BMI [8, 9]. Childhood SEP has been found to be an independent predictor of BMI among women [11, 12] but not in men $[12,13]$. Few recent studies have explored whether childhood SEP contributes to racial disparities in BMI trajectories among women [10-14]. For example, in the Alameda County study, Black women were heavier at baseline and had steeper BMI trajectories over time than White women. The racial difference in baseline weight among women was reduced only slightly after adjustment of lifecourse SEP variables. In contrast, racial differences in BMI among men were lower than those for 
women and completely accounted for after adjustment of lifecourse SEP [8]. Results from Monitoring the Future study also suggest that racial differences in BMI are more pronounced and are explained by SEP differences to a lesser degree among women for all age cohorts [10]. However, the pathways through which multiple dimensions of lifecourse SEP may contribute to racial disparities in BMI trajectories among women have not been extensively explored.

The objectives of this study were to (1) assess the relationship between lifecourse SEP and trajectories of BMI among women by age cohorts; (2) assess the evidence for the pathway model for the influence of childhood SEP on BMI trajectories; and (3) explore whether lifecourse socioeconomic disadvantage contributes to racial differences in adult BMI.

\section{Materials and Methods}

\section{Study Population}

The study utilizes updated data (made available in 2011) from four waves of the Americans' Changing Lives (ACL) study, conducted initially in 1986 (wave 1 (W1)), with follow-up interviews in 1989, 1994, and 2002 [15] (Fig. 1). The sampling design used in ACL was a multistage, stratified area probability sampling of noninstitutionalized adults aged 25 and older. The sample for these analyses was restricted to women who reported their race as either Black or White $(n=2,194)$. Post-stratification weights were used to adjust for differential probabilities of selection by age and race so that the results are representative of the US population in 1986 [15].
Measures

$B M I$ Body mass index was calculated by dividing selfreported weight in kilograms by self-reported height in meters squared. BMI is a time-dependent continuous variable and data were utilized from all four waves.

Lifecourse SEP variables Information on childhood SEP was collected in wave 2 and included father's education and perceived childhood family status (PCFS). Information on adult SEP included completed education at W1, family income (continuous, time varying), wealth (continuous, time varying), and an index of financial security (continuous, time varying) (Appendix A). Income was only reported as a categorical variable in $\mathrm{W} 1$; therefore, midpoints of each respective category were used as a measure of the respondent's income for that year. To facilitate comparison across time, income was adjusted for inflation using the Consumer Price Index to represent value in 1986 dollars. Log-transformed values were used in the regression analyses. Wealth was based on reported values of real estate, business or farm, retirement accounts, savings/investments, cars, and other assets. The Financial Security Index provided in the ACL survey was constructed from the survey questions: (1) How satisfied are you with your/your family's present financial situation; (2) How difficult is it for you/ your family to meet the monthly payments on your [family's] bills. Higher scores on the resulting scale reflect higher security.

W1 information on age, sex, race, parity, birth year, and height were the other covariates utilized in the analyses. Race was coded as Black or White.
Fig. 1 Americans' Changing Lives Study (1986-2002)Survey Design and Response Rates

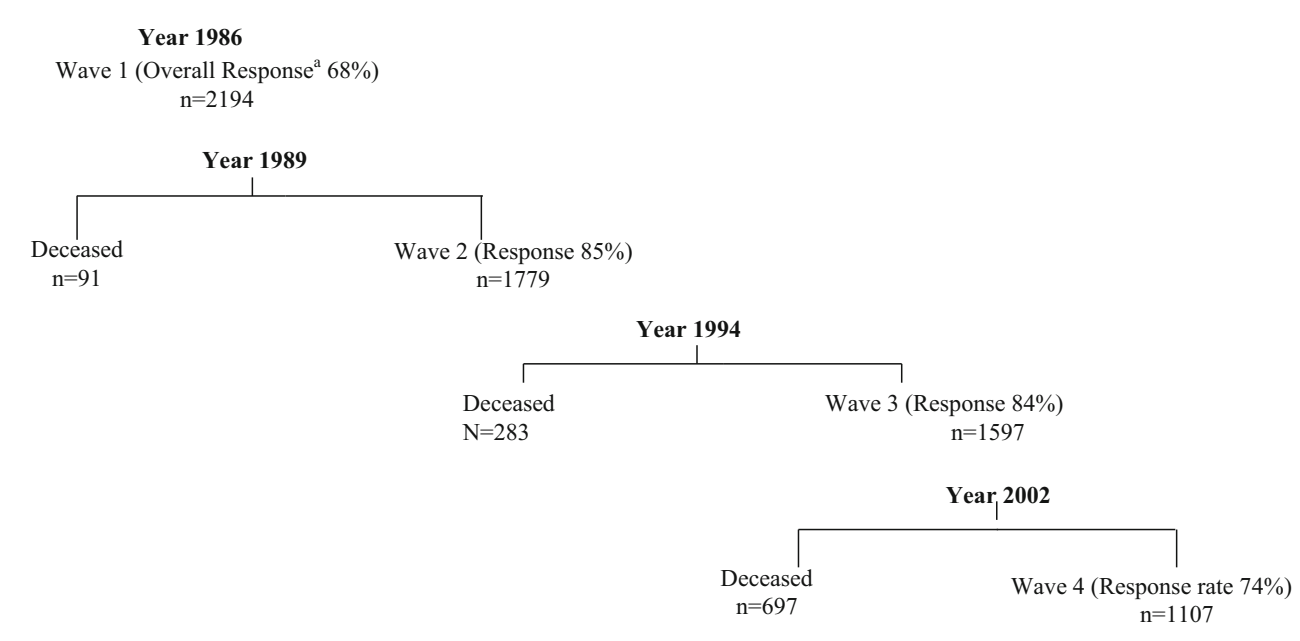

a'Overall response rate for the Americans' Changing Lives Study, response data for subsample were not made available by the data stewards. 
Statistical Analyses

Time invariant variables were centered at their mean and time varying predictors at their value during the year of first wave of data collection to facilitate interpretation [16]. For time varying covariates such as income, wealth, and financial security, both the W1 value and the centered variables were entered in the models to assess the effect of $\mathrm{W} 1$ value as well as change in these variables over time. Age was centered at 25 years which was the minimum age at $\mathrm{W} 1$.

Inference by multiple imputation [17] was utilized to address uncertainty due to missing values caused by attrition as well as arbitrary item nonresponse. As the missingness mechanism underlying item nonresponse and attrition was deemed to be missing at random [17], inference by MI was chosen as it has been repeatedly shown to lead to valid and optimal inferential quality. The underlying imputation model was a multivariate normal model with unstructured covariance matrix to preserve the longitudinal aspect of the study. As Blacks had higher rates of missingness for some SEP variables such as father's education ( $26 \%$ as compared to $12 \%$ for White women), we included race as well as other possible predictors of missingness along with all the covariates for the multivariate model into our imputation model. All models had relative efficiencies greater than 0.90 , which suggests that the number of imputations was sufficient to achieve estimates with standard errors that captured most of the variation in the underlying sampling distribution. Mixed-effects models were used to estimate the average time-related BMI trajectories [18]. The basic model can be represented as

$\mathrm{BMI}_{i j}=\beta_{00}+\beta_{10}$ Time $+u_{0 i}+u_{1 i} *$ time $+\varepsilon_{i j}$

where $\mathrm{BMI}_{i j}$ is $\mathrm{BMI}$ for individual $i$ at time $j ; \beta_{00}$ is the average BMI at time 0 (intercept/W1); and $\beta_{10}$ is the average annual rate of change of BMI (slope). All models allowed both the intercept and time effect to vary randomly across persons because it significantly improved the model fit. The errors $u$ capture random variance in the intercept and slope values across persons, and $\varepsilon_{i j}$ represents random error for individual $i$ at time $j$. Using this framework, the associations between lifecourse SEP, W1 BMI, and BMI change may be assessed together. The effect of each individual SEP variable on BMI at W1 was assessed initially. To assess the effects of SEP on the BMI change, interaction terms with time were added for each variable.

BMI trajectories for Blacks and Whites by $\mathrm{W} 1$ age groups were plotted using a simple mixed-effects model with these demographic variables as predictors of BMI at $\mathrm{W} 1$ and BMI slope. Based on the difference in pattern of BMI trajectories, we stratified the multivariate analyses by baseline age cohorts into younger women $($ age $<40)$ and older women (aged 40 and older in 1986). For each cohort, the effect of each individual SEP variable was assessed on BMI at W1 and BMI slope. For multivariable analyses, those SEP variables and covariates that were significant at alpha $=0.20$ level in the individual SEP analyses were included in the preliminary full model. Purposeful selection procedures using backward elimination were then used to retain those variables that were independently associated with BMI at W1 and BMI slope at alpha= 0.05 level [19]. A variable was retained in the model as a confounder if the partial regression coefficient of the other predictors varied by more than $10 \%$ when the variable was deleted from the model [20]. The final multivariate model was the most parsimonious model containing all significant predictors and confounders using this approach. All statistical tests were two sided. All statistical analysis was conducted in SAS 9.2 (Cary, NC). The research was approved by the University at Albany Institutional Review Board.

\section{Results}

Post-stratification weights were used to calculate means and proportions for each of the covariates. The weighting strategy ensures that these design-based estimates are nationally representative of noninstitutionalized adults 25 years or older in 1986. The analysis sample consisted of predominantly White women $(87.5 \%)$ with a mean age of 49 years at W1 (Table 1 ). Mean age of the younger and older cohorts were 31.87 $( \pm 4.30)$ years and $63.60( \pm 12.14)$ years, respectively. Although a higher proportion of subjects reported high PCFS (73\%), almost a third of the subjects reported having a father who had not completed high school. The mean BMI was $25.16 \mathrm{~kg} / \mathrm{m}^{2}$ in 1986 which increased over time to $27.04 \mathrm{~kg} / \mathrm{m}^{2}$ in 2002 . Income (inflation adjusted) and wealth and financial security increased over time. We only found modest correlations between the different SEP variables; for example, the highest correlation was between income and wealth (Pearson's correlation $=0.53$ ); father's education and a subject's own education were also modestly correlated (Pearson's correlation $=0.36$ ) (Appendix B, Table B2). These correlation statistics were consistent across gender and age cohorts (Appendix B, Table B3-B6). These results suggest that the lifecourse SEP variables should not be precluded from simultaneous inclusion in multivariable models.

\section{Trajectories of BMI by Race and Age}

Unadjusted BMI trajectories for White and Black females for ages $25,40,55$, and 70 were plotted to represent young adults, middle age, and older age groups (Fig. 2). Black women had higher W1 BMI as compared to White women at all ages and over the full study period. Among women less than 40, there was also a small racial difference in slope, with BMI 
Table 1 Descriptive statistics for women in the Americans' Changing Lives cohort (1986-2002)

\begin{tabular}{|c|c|c|c|c|c|c|c|c|}
\hline \multirow[b]{2}{*}{ Response rates } & \multicolumn{2}{|l|}{ Wave 1} & \multicolumn{2}{|l|}{ Wave 2} & \multicolumn{2}{|l|}{ Wave 3} & \multicolumn{2}{|l|}{ Wave 4} \\
\hline & $N$ & $\%$ & $N$ & $\%$ & $N$ & $\%$ & $N$ & $\%$ \\
\hline Responders & 2,194 & 100 & 1,779 & 81.08 & 1,597 & 72.79 & 1,107 & 50.46 \\
\hline Dead & & & 91 & 4.15 & 283 & 12.9 & 390 & 17.78 \\
\hline Nonresponders & & & 324 & 14.77 & 314 & 14.31 & 697 & 31.77 \\
\hline Variables & Mean $^{\mathrm{a}}$ & Std.dev ${ }^{\mathrm{a}}$ & Mean $^{\mathrm{a}}$ & Std.dev ${ }^{\mathrm{a}}$ & Mean $^{a}$ & Std.dev ${ }^{\mathrm{a}}$ & Mean $^{a}$ & Std.dev ${ }^{\mathrm{a}}$ \\
\hline \multicolumn{9}{|c|}{ Time varying variables } \\
\hline BMI & 25.16 & 4.62 & 25.55 & 4.84 & 26.11 & 5.11 & 27.04 & 5.83 \\
\hline Missing $(n, \%)$ & & & 415 & 18.92 & 597 & 27.21 & 1,087 & 49.54 \\
\hline Income $^{b}$ & $26,440.54$ & $18,344.75$ & $30,388.17$ & $27,547.31$ & $30,009.30$ & $29,271.02$ & $37,148.91$ & $68,449.65$ \\
\hline Missing $(n, \%)$ & & & 415 & 18.92 & 597 & 27.21 & 1,088 & 49.59 \\
\hline Financial security & -0.02 & 0.93 & 0.08 & 0.89 & 0.07 & 0.93 & 0.24 & 0.95 \\
\hline Missing $(n, \%)$ & & & 415 & 18.92 & 713 & 32.50 & 1153 & 52.55 \\
\hline Wealth & 1.30 & 1.46 & 1.47 & 1.60 & 2.09 & 1.72 & 3.28 & 1.94 \\
\hline Missing $(n, \%)$ & 184.00 & 8.39 & 530 & 24.16 & 680 & 30.99 & 1217 & 55.47 \\
\hline \multicolumn{9}{|l|}{ Time stable variables } \\
\hline \multirow[t]{2}{*}{ Age } & 48.66 & 15.35 & & & & & & \\
\hline & $N$ & $\%^{\mathrm{a}}$ & & & & & & \\
\hline \multicolumn{9}{|l|}{ Race } \\
\hline Whites & 1,416 & 87.49 & & & & & & \\
\hline Blacks & 778 & 12.51 & & & & & & \\
\hline \multicolumn{9}{|c|}{ Perceived childhood financial status } \\
\hline High & 1,542 & 73.69 & & & & & & \\
\hline Low & 234 & 10.39 & & & & & & \\
\hline Missing & 418 & 15.92 & & & & & & \\
\hline \multicolumn{9}{|l|}{ Father's education } \\
\hline$\geq 12$ years & 532 & 41.05 & & & & & & \\
\hline$<12$ years & 957 & 35.91 & & & & & & \\
\hline Missing & 705 & 23.04 & & & & & & \\
\hline \multicolumn{9}{|l|}{ Education } \\
\hline$<12$ years & 846 & 26.06 & & & & & & \\
\hline$\geq 12$ years & 1,348 & 73.09 & & & & & & \\
\hline
\end{tabular}

$B M I$ body mass index

${ }^{a}$ Design-based estimates of means, standard deviation and percentage represent 1986 US population

${ }^{\mathrm{b}}$ Inflation adjusted to represent 1986 dollars

increasing more steeply over time among Blacks compared to Whites. The BMI trajectories increase until age 55 after which they are stable. There was a decline in BMI after age 70 . Women who were aged 25 in 1986 had a higher BMI at age 40 (in 2002) than the older cohort of women who were 40 years in 1986 .

Lifecourse Socioeconomic Position in the Younger Cohort

Using individual SEP models (i.e., each single SEP variable by itself) to ascertain the association between individual lifecourse SEP factors and W1 BMI and slope, we found that except for PCFS, all other lifecourse SEP factors under study were related to W1 BMI (Table 2, column 2). Higher wealth and financial security were the only factors associated with a more gradual increase in BMI over time.

In the race-only model, Black women had a higher W1 BMI $\left(+2.62 \mathrm{~kg} / \mathrm{m}^{2}(95 \% \mathrm{CI}+1.71,+3.53)\right)$ and a higher slope of BMI $\left(+0.73 \mathrm{~kg} / \mathrm{m}^{2} /\right.$ decade $\left.(95 \% \mathrm{CI}+0.17,+1.29)\right)$ than White women. In multivariable models, this racial difference in W1 BMI was attenuated to $2.06 \mathrm{~kg} / \mathrm{m}^{2}(95 \% \mathrm{CI}+1.12,+$ $3.00)$. Based on the modeling strategy outlined in the methods section, Table 2, column 3, presents the estimates and confidence intervals for the most parsimonious model including those lifecourse SEP variables that were deemed to be statistically independent predictors of W1 BMI and BMI slope 


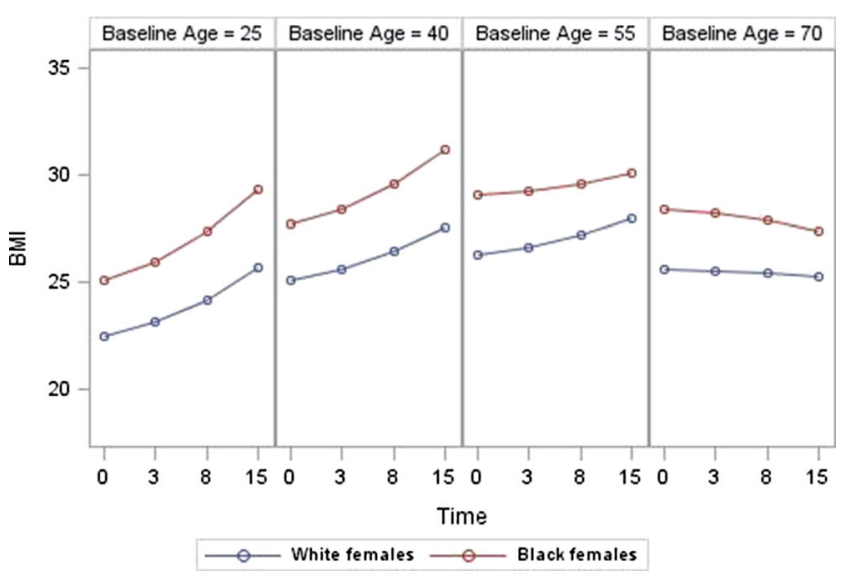

Fig. 2 BMI trajectories by age among Black and White women in the ACL study (1986-2002)

during the study period. Among women $<40$ years, education and income were the strongest statistically independent predictors of W1 BMI. Women who had completed high school had a $1.34 \mathrm{~kg} / \mathrm{m}^{2}(95 \% \mathrm{CI}-2.53,-0.15)$ lower W1 BMI than women with lower education. With each one unit increase in log income, W1 BMI was lower by $0.78 \mathrm{~kg} / \mathrm{m}^{2}$ (95\% CI $-1.32,-0.25)$. None of the SEP predictors were associated with slope of BMI in a multivariable model. Therefore, lifecourse SEP did not seem to account for the racial differences in slope.

\section{Lifecourse Socioeconomic Position in Older Cohort of Women}

Among women who were 40 years and older at W1, Black women had a higher W1 BMI than white women $(+2.68 \mathrm{~kg} /$ $\left.\mathrm{m}^{2}(95 \% \mathrm{CI}+2.12,3.24)\right)$ but had a more gradual increase (in middle age) and a steeper decline (at older ages) $\left(-0.42 \mathrm{~kg} / \mathrm{m}^{2} /\right.$ decade $(95 \%$ CI $-0.81,-0.03)$ ) (Table 3). On multivariable adjustment, the racial difference in W1 BMI was attenuated to $2.00 \mathrm{~kg} / \mathrm{m}^{2}(95 \% \mathrm{CI}+1.40,+2.59)$ while the racial difference in BMI slope was no longer significant. Table 3, column 3, presents the estimates and confidence intervals for the most parsimonious model including those lifecourse SEP variables that were deemed to be statistically independent predictors of W1 BMI and BMI slope for the older cohort of women. Father's education, respondent's education, and wealth were significant independent predictors of W1 BMI while wealth was the only significant predictor of slope in the final model for change in BMI. Women over 40 who had a high father's education had a $-0.78 \mathrm{~kg} / \mathrm{m}^{2}(95 \% \mathrm{CI}-0.06,-1.50)$ lower $\mathrm{BMI}$ at W1 than those with lower parental education. Similarly, women who completed high school had a $-1.08 \mathrm{~kg} / \mathrm{m}^{2}$ $(95 \%$ CI $-0.50,-1.65)$ lower BMI than those with lower education levels. Those with high $\mathrm{W} 1$ wealth had a lower BMI at W1 $\left(-0.26 \mathrm{~kg} / \mathrm{m}^{2}(95 \% \mathrm{CI}-0.43,-0.08)\right)$ but had a smaller yet statistically significant greater gain in BMI over time $\left(+0.12 \mathrm{~kg} / \mathrm{m}^{2} /\right.$ decade $\left.(95 \% \mathrm{CI}+0.03,+0.22)\right)$.

The results of the final models were compared with models including health behaviors such as number of alcoholic drinks/month, number of cigarettes smoked, and physical activity index and found that racial differences were attenuated further, but associations of lifecourse SEP variables were consistent with those for models excluding health behaviors (results not presented).

\section{Discussion}

In this large population-based dataset, SEP variables were important predictors of $\mathrm{W} 1 \mathrm{BMI}$ but not for slope of BMI over time. The racial differences in BMI trajectories among women over time were partly explained by differences in lifecourse SEP. This study is one of the first to explore associations between multiple SEP predictors and BMI by age cohorts.

Childhood SEP, as measured by father's education, was an independent predictor of BMI among the older cohort but not among the younger cohort. Other studies have not explored whether lifecourse predictors of BMI are different by birth cohorts. This along with incomplete control of adult SEP may have contributed to the conflicting results of childhood SEP in previous literature. For example, the Monitoring the Future study, among 10,956 , predominantly White participants, found that low father's education was related to high W1 BMI and higher rate of gain in BMI from 1986 to 2004 [10]. Baltrus et al., in their sample of 1,657 women from the Alameda County study, found that childhood SEP had an independent effect on change in BMI among women aged 17-30 after adjusting for education and occupation [12]. Since these authors did not assess other SEP factors such as income, wealth, or financial security in these studies, they had a more limited ability to control for the effect of adult SEP while evaluating the independent role of childhood SEP. Our study adds to the literature by demonstrating that childhood SEP remains an independent predictor of BMI among the older cohort of women even after a more comprehensive control of adult SEP than previous literature.

The importance of education as a lifecourse SEP predictor is supported by results from other studies. Clarke et al. found low father's education as well as low individual education were both related to high W1 BMI and higher rate of gain in BMI [10]. Similarly, in the Alameda County study, education was the most important predictor of adult BMI [12]. Our results are consistent with previous literature showing that education may be an important predictor of racial differences in obesity among females but the influence of education among racial subgroups in males has been equivocal $[10,21]$. 
Table 2 Effect of lifecourse SEP variables on BMI at Wave 1 and change in BMI in younger cohort-The Americans' Changing Lives Study 1986-2002 $(N=573)$

All models adjusted for age, age*time, height, and parity; all models use post-stratification weights to provide design-based estimates

$* * * p$ value $<0.0001$

$* * p$ value $<0.001, * p$ value $<0.05$

\begin{tabular}{|c|c|c|}
\hline BMI at Wave 1 & $\begin{array}{l}\text { Individual SEP Models } \\
\text { Estimate }(95 \% \mathrm{CI})\end{array}$ & $\begin{array}{l}\text { Final Predictive Model } \\
\text { Estimate }(95 \% \mathrm{CI})\end{array}$ \\
\hline \multicolumn{3}{|l|}{ Race } \\
\hline Blacks & $2.62(1.71,3.53)^{* * *}$ & $2.06(1.12,3.00)^{* * *}$ \\
\hline \multicolumn{3}{|l|}{ Whites } \\
\hline \multicolumn{3}{|c|}{ Perceived Childhood Family Status } \\
\hline Better off/Average & $-0.42(-1.72,0.88)$ & \\
\hline \multicolumn{3}{|l|}{ Worse } \\
\hline \multicolumn{3}{|l|}{ Father's Education } \\
\hline$\geq 12$ years & $-1.35(-2.38,-0.31)^{* *}$ & \\
\hline \multicolumn{3}{|l|}{$<12$ years } \\
\hline \multicolumn{3}{|l|}{ Education } \\
\hline$\geq 12$ years & $-2.21(-3.38,-1.04)^{* *}$ & $-1.34(-2.53,-0.15)^{*}$ \\
\hline \multicolumn{3}{|l|}{$<12$ years } \\
\hline Wave 1 Income & $-1.33(-1.82,-0.83)^{* * *}$ & $-0.78(-1.32,-0.25)^{* *}$ \\
\hline Wave 1 Wealth & $-0.37(-0.75,0.02)$ & \\
\hline Wave 1 Financial Security & $-0.54(-0.95,-0.14)^{* *}$ & \\
\hline \multicolumn{3}{|l|}{ Change in BMI/year } \\
\hline \multicolumn{3}{|l|}{ Race } \\
\hline Blacks & $0.73(0.17,1.29)^{* *}$ & $0.73(0.17,1.29)^{* *}$ \\
\hline \multicolumn{3}{|l|}{ Whites } \\
\hline \multicolumn{3}{|c|}{ Perceived Childhood Family Status } \\
\hline Better off/Average & $0.33(-0.22,0.89)$ & \\
\hline \multicolumn{3}{|l|}{ Worse } \\
\hline \multicolumn{3}{|l|}{ Father's Education } \\
\hline$\geq 12$ years & $-0.11(-0.60,0.37)$ & \\
\hline \multicolumn{3}{|l|}{$<12$ years } \\
\hline \multicolumn{3}{|l|}{ Education } \\
\hline$\geq 12$ years & $-0.27(-0.96,0.43)$ & \\
\hline \multicolumn{3}{|l|}{$<12$ years } \\
\hline Wave 1 Income & $-0.21(-0.52,0.09)$ & \\
\hline Change in Income & $-0.05(-0.28,0.19)$ & \\
\hline Wave 1 Wealth & $-0.29(-0.47,-0.10)^{* *}$ & \\
\hline Change in Wealth & $-0.08(-0.16,0.00)$ & \\
\hline Wave 1 Financial Security & $-0.39(-0.65,-0.13)^{* *}$ & \\
\hline Change in Financial Security & $-0.05(-0.25,0.15)$ & \\
\hline
\end{tabular}

Income was an important predictor for the younger cohort, but wealth was more important for older adults. Income is thought to be a predictor of a healthy lifestyle including positive dietary choices and leisure time physical activity partly because it provides access to material goods and services. Prior studies have found that financial security is associated with obesity independently of income [22]. Resources accumulated throughout the lifecourse as assessed by childhood SEP and wealth may play a greater role among older women. Access to resources related to healthy lifestyle choices may not be as closely related to income among older women, because informal social networks, government subsidies for housing and medical care, and accumulated assets may provide resources that were obtained with earned income at earlier ages.

Racial differences in BMI persist even after adjusting for lifecourse SEP. There were significant racial disparities in BMI trajectories among both older and younger women. Adjustment for lifecourse SEP attenuated some of these racial disparities but did not eliminate them entirely. Clarke et al. found significant racial disparities in BMI [10] which were attenuated very slightly after adjustment for self and parent's education. Baltrus et al. found [8] that childhood SEP accounted for some of the racial difference in BMI but large differences persisted even after controlling for cumulative 
Table 3 Effect of lifecourse SEP variables on BMI at Wave 1 and change in BMI in older cohortThe Americans' Changing Lives Study 1986-2002 $(N=1621)$
All models adjusted for age, age*time, height, and parity; all models use post-stratification weights to provide design-based estimates

$* * * p$ value $<0.0001$

$* * p$ value $<0.001, * p$ value $<0.05$

\begin{tabular}{|c|c|c|}
\hline BMI at Wave 1 & $\begin{array}{l}\text { Individual SEP models } \\
\text { Estimate }(95 \% \mathrm{CI})\end{array}$ & $\begin{array}{l}\text { Final predictive model } \\
\text { Estimate }(95 \% \mathrm{CI})\end{array}$ \\
\hline \multicolumn{3}{|l|}{ Race } \\
\hline Blacks & $2.68(2.12,3.24)^{* * *}$ & $2.00(1.40,2.59)^{* * *}$ \\
\hline \multicolumn{3}{|l|}{ Whites } \\
\hline \multicolumn{3}{|c|}{ Perceived Childhood Family Status } \\
\hline Better off/Average & $0.36(-0.361 .08)$ & \\
\hline \multicolumn{3}{|l|}{ Worse } \\
\hline \multicolumn{3}{|l|}{ Father's Education } \\
\hline$\geq 12$ years & $-1.50(-2.25,-0.76)^{* * *}$ & $-0.78(-0.06,-1.50)^{*}$ \\
\hline \multicolumn{3}{|l|}{$<12$ years } \\
\hline \multicolumn{3}{|l|}{ Education } \\
\hline$\geq 12$ years & $-2.17(-2.70,-1.64)^{* * *}$ & $-1.08(-0.50,-1.65)^{* *}$ \\
\hline \multicolumn{3}{|l|}{$<12$ years } \\
\hline Wave 1 Income & $-0.95(-1.25,-0.65)^{* * *}$ & \\
\hline Wave 1 Wealth & $-0.60(-0.77,-0.44)^{* * *}$ & $-0.26(-0.43,-0.08)^{* *}$ \\
\hline Wave 1 Financial Security & $-0.76(-1.01,-0.50)^{* * *}$ & \\
\hline \multicolumn{3}{|l|}{ Change in $\mathrm{BMI} /$ year } \\
\hline \multicolumn{3}{|l|}{ Race } \\
\hline Blacks & $-0.42(-0.81,-0.03)^{*}$ & $-0.27(-0.67,0.13)$ \\
\hline \multicolumn{3}{|l|}{ Whites } \\
\hline \multicolumn{3}{|c|}{ Perceived Childhood Family Status } \\
\hline Better off/Average & $0.02(-0.45,0.49)$ & \\
\hline \multicolumn{3}{|l|}{ Worse } \\
\hline \multicolumn{3}{|l|}{ Father's Education } \\
\hline$\geq 12$ years & $0.15(-0.25,0.54)$ & \\
\hline \multicolumn{3}{|l|}{$<12$ years } \\
\hline \multicolumn{3}{|l|}{ Education } \\
\hline$\geq 12$ years & $0.45(0.12,0.78)^{* * *}$ & \\
\hline \multicolumn{3}{|l|}{$<12$ years } \\
\hline Wave 1 Income & $-0.16(-0.35,0.16)$ & \\
\hline Change in Income & $0.00(-0.21,0.20)$ & \\
\hline Wave 1 Wealth & $0.14(0.04,0.24)^{*}$ & $0.12(0.03,0.22)^{* *}$ \\
\hline Change in Wealth & $0.00(-0.07,0.06)$ & \\
\hline Wave 1 Financial Security & $0.12(-0.08,0.31)$ & \\
\hline Change in Financial Security & $0.02(-0.12,0.15)$ & \\
\hline
\end{tabular}

SEP across the lifecourse [8]. The results of the present study are broadly consistent with these findings.

Despite considerable racial differences in wealth and financial security, the contribution of these variables to racial disparities in health has not been studied extensively. It has been postulated that higher rates of obesity in Black women may be attributed to overeating as a coping mechanism for multiple chronic stressors including poverty [23]. This study adds to the existing literature by evaluating multiple dimensions of lifecourse SEP and demonstrating the persistence of racial disparities despite adjustment for multiple measures of SEP. Further research is needed to assess whether other factors such as psychological stressors like discrimination and differences in cultural norms related to diet and physical activity contribute to these disparities in conjunction with differences in SEP.

The present study had several strengths. Retrospective measures of childhood SEP and young adult SEP (as measured by education), as well as prospective measures of income, wealth, and financial security at four time points in adulthood, spanning 16 years were used to measure lifecourse SEP. Relationships between SEP and adult health outcomes can be better characterized using this large array of variables. The use of multiple measures allowed more complete control for SEP when examining racial differences, as single measures of SEP may not be equivalent in Blacks and Whites [24]. For instance, Black women earn less money than their White 
counterparts with equivalent levels of education [25]. Blacks also have been shown to pay more for certain basic expenses including food, automobile insurance, and mortgages [26-28] as well as for health care [29]. Higher prices mean lower purchasing power and consequently a lower standard of living for Blacks with incomes equivalent to those of Whites. Inclusion of wealth along with income more comprehensively reflects economic resources, including lifelong earnings, past financial losses, and intergenerational transfers [30, 31]. The study extends previous research by analyzing racial differences in BMI trajectories and more comprehensively assessing the influences of lifecourse SEP over change in BMI.

According to the most recent guidelines by the American Heart Association, American College of Cardiology, and The Obesity Society, the condition of obesity has been classified as a disease [32]. However, for the purposes of this research, we considered BMI as a consequence of lifestyle behaviors such as diet and physical activity, rather than as a measure of obesity [33,34]. Consequently, results adjusted for other behavioral factors such as physical activity, smoking status, and alcohol were not presented as we believe they would be in the causal pathway and therefore lead to overadjustment if controlled for in the analysis.

Our use of father's education as an indicator of childhood SEP is advantageous as this variable is less likely to change than occupation or income after young adulthood. Occupational status was not used as a predictor in the analyses as it may not be comparable across divisions of race/ethnicity especially among women. Occupation also cannot readily be used for social groups outside of the recognized paid labor force [30] which may include the unemployed, homemakers, persons employed informally (e.g., childcare providers) or in illegal sectors, and the retired.

There are some important limitations of this study that must be considered in interpreting these results. Adult recall was used to measure early life circumstances. However, previous research has confirmed the quality of retrospective childhood SEP reports [35] especially for parental education [36]. Older individuals may be less likely to recall childhood circumstances correctly than younger individuals as life experience events and the aging process may have an influence on the recall of this information. However, research has shown good internal and external consistency for broad measures of childhood SEP among older individuals [37]. Blacks had a higher rate of missing data for father's education than White women ( $26 \%$ as compared to $12 \%$ ). In the ACL data, a higher proportion of Black women did not live with parents; however, very few women among these (21 Black women and 10 White women) did not know their parents in childhood (and would therefore be unaware of their father's education status). We therefore expect minimal bias due to differential missingness for parental education. Further, our multivariate imputation model included all the predictors in the study as well as those variables deemed to contribute to the missing data such as race and age. Self-reported weight and height may underestimate the true BMI. However, the sensitivity (83-89\%) and specificity (95-98\%) of self-reported BMI have been high among females and racial subgroups and the overall underestimation ranges from $-0.73 \mathrm{~kg} / \mathrm{m} 2$ for Blacks to -0.90 for Whites [38]. There is also evidence that associations between BMI and SEP factors do not change when BMI is corrected for bias due to self-report [4]. Therefore, we expect only a modest impact on our estimates of racial differences in trajectories due to underestimation of BMI using selfreported weight and height. There is some evidence that those with persistent overweight since childhood may achieve lower SEP during adulthood [39] especially in women [40]. However, overweight and obesity may affect some socioeconomic measures like income more than others such as education and wealth $[39,40]$. Therefore, the use of multiple measures of adult SEP may limit the resulting bias due to reverse causality.

We found only modest correlations between the different measures of lifecourse SEP, and previous literature suggests that multiple SEP variables can be adjusted for in the same model without issues with collinearity [41]. We formally tested multicollinearity in the models by assessing the variance inflation factor (VIF) of each variable included in the multivariate model. The VIF is a measure used to assess the potential impact on the standard errors due to multicollinearity, and VIF values $>10$ are considered indicative of multicollinearity. VIF values for all SEP variables in the ACL data were less than 3. Our use of mixed models also allowed for the analyses of multiple exposures simultaneously. Finally, the use of centering strategies has also been shown to reduce multicollinearity issues resulting from correlated variables. Sensitivity analysis using income-only and wealth-only models did not change our results and conclusions for either cohort.

Lifecourse SEP did not predict change in BMI in the ACL study. Although the ACL study had 4 waves across 16 years, these measurements may still be inadequate to accurately capture the precise BMI trajectories and this measurement error in the outcome may have led to underestimation of lifecourse SEP associations. Community level socioeconomic measures were not assessed; however, previous reports found that most of the variation in BMI is at the individual level rather than at the neighborhood level $[4,5]$.

Our results suggest that separate components of lifecourse SEP are important predictors of adult BMI in women. Racial differences in BMI can be partly explained by differences in lifecourse SEP. Further research on socioeconomic predictors of health outcomes should incorporate multiple measures of SEP over the lifecourse to provide insights into the mechanisms of these findings. 
Acknowledgments This research was funded by the National Institutes of Health, National Institute on Aging (grant number R01 AG031109, "Health Behaviors and Lifestyles in Old Age in the United States and Japan"), and National Institute on Minority Health and Health Disparities (grant number P20 MD003373, "Exploratory Center on Minority Health and Health Disparities in Smaller Cities").

Conflict of Interest The authors Insaf, Shaw, Yucel, Chasan-Taber, and Strogatz declare that they have no conflict of interest.

Ethical Standards No animal or human studies were carried out by the authors for this article. The analysis for this project was conducted using nonidentifiable data from the Americans' Changing Lives Study which is publicly available from the Inter-University Consortium for Political and Social Research. The research for the current article was approved by the University at Albany Institutional Review Board.

\section{References}

1. Ogden CL, Lamb MM, Carroll MD, Flegal KM. Obesity and socioeconomic status in adults: United States, 2005-2008. NCHS Data Brief. 2010(50):1-8.

2. Flegal KM, Carroll MD, Ogden CL, Curtin LR. Prevalence and trends in obesity among US adults, 1999-2008. JAMA. 2010;303(3):235-41.

3. Mujahid MS, Diez Roux AV, Borrell LN, Nieto FJ. Cross-sectional and longitudinal associations of BMI with socioeconomic characteristics. Obes Res. 2005;13(8):1412-21.

4. Ruel E, Reither EN, Robert SA, Lantz PM. Neighborhood effects on BMI trends: examining BMI trajectories for Black and White women. Health Place. 2010;16(2):191-8.

5. Robert SA, Reither EN. A multilevel analysis of race, community disadvantage, and body mass index among adults in the US. Soc Sci Med. 2004;59(12):2421-34.

6. Ben-Shlomo Y, Kuh D. A life course approach to chronic disease epidemiology: conceptual models, empirical challenges and interdisciplinary perspectives. Int J Epidemiol. 2002;31(2):285-93.

7. Ferraro KF, Shippee TP. Aging and cumulative inequality: how does inequality get under the skin? Gerontologist. 2009;49(3):333-43.

8. Baltrus PT, Lynch JW, Everson-Rose S, Raghunathan TE, Kaplan GA. Race/ethnicity, life-course socioeconomic position, and body weight trajectories over 34 years: the Alameda County Study. Am J Public Health. 2005;95(9):1595-601.

9. Glymour MM, Avendano M, Haas S, Berkman LF. Lifecourse social conditions and racial disparities in incidence of first stroke. Ann Epidemiol. 2008;18(12):904-12.

10. Clarke P, O'Malley P, Johnston L, Schulenberg J. Social disparities in BMI trajectories across adulthood by gender, race/ethnicity and lifetime socio-economic position: 1986-2004. Int J Epidemiol. 2009;38(2):499-509.

11. Ball K, Mishra G. Whose socioeconomic status influences a woman's obesity risk: her mother's, her father's, or her own? Int J Epidemiol. 2006;35(1):131-8.

12. Baltrus P, Everson-Rose S, Lynch J, Raghunathan T, Kaplan G. Socioeconomic position in childhood and adulthood and weight gain over 34 years: the Alameda County Study. Ann Epidemiol. 2007;17(8):608-14.

13. Giskes K, van Lenthe F, Turrell G, Kamphuis C, Brug J, Mackenbach J. Socioeconomic position at different stages of the life course and its influence on body weight and weight gain in adulthood: a longitudinal study with 13-year follow-up. Obesity (Silver Spring). 2008;16(6):1377-81.
14. James SA, Fowler-Brown A, Raghunathan TE, Van Hoewyk J. Lifecourse socioeconomic position and obesity in African American Women: the Pitt County Study. Am J Public Health. 2006;96(3): 554-60.

15. House JS. Americans' Changing Lives: Waves I, II, III, and IV, 1986, 1989, 1994, and 2002. Ann Arbor,MI: Inter-university Consortium for Political and Social Research [distributor], 2008.

16. Diggle P, Liang K, Zeger S. Analysis of longitudinal data. 2nd Edition ed: Oxford University Press; 2002.

17. Little ARJ, Rubin DB, Little RJAaR DB. Statistical analysis with missing data. 2nd ed. New York: Wiley \&amp; Sons; 2002.

18. Singer J, Willett J. Applied longitudinal data analysis: modeling change and event occurrence. New York: Oxford University Press; 2003.

19. Hosmer DW, Lemeshow S, R S. Applied logistic regression: Wiley; 3 edition (April 1, 2013); 2013.

20. Weng H, Hsueh Y, Messam L, Hertz-Picciotto I. Methods of covariate selection: directed acyclic graphs and the change-in-estimate procedure. Am J Epidemiol. 2009;169(10):1182-90.

21. Scharoun-Lee M, Adair LS, Kaufman JS, Gordon-Larsen P. Obesity, race/ethnicity and the multiple dimensions of socioeconomic status during the transition to adulthood: a factor analysis approach. Soc Sci Med. 2009;68(4):708-16.

22. Block JP, He Y, Zaslavsky AM, Ding L, Ayanian JZ. Psychosocial stress and change in weight among US adults. Am J Epidemiol. 2009;170(2):181-92.

23. Lovejoy M. Disturbances in the social body. Gend Soc. 2001;15(2): 239-61.

24. Kaufman J, Cooper R, McGee D. Socioeconomic status and health in blacks and whites: the problem of residual confounding and the resiliency of race. Epidemiology. 1997;8(6):621-8.

25. Kerby S. How pay inequity hurts women of color. Center for American Progress, 2013.

26. Cooper R, David R. The biological concept of race and its application to public health and epidemiology. J Health Polit Policy Law. 1986;11(1):97-116.

27. Taylor J, Berenbaum D, Silver J, Mantcheva D. Income is no shield: against racial differences in lending II: a comparison of high-cost lending in america's metropolitan and rural areas. National Community Reinvestment Coalition, 2008.

28. Kaufman P, MacDonald J, Lutz S, Smallwood D. Do the poor pay more for food? Item selection and price differences affect low-income household food costs. Food and Rural Economics Division, Economic Research Service, U.S. Department of Agriculture; 1997.

29. Suthers K. Evaluating the economic causes and consequences of racial and ethnic health disparities. American Public Health Association, 2008.

30. Krieger N, Williams DR, Moss NE. Measuring social class in US public health research: concepts, methodologies, and guidelines. Annu Rev Public Health. 1997;18:341-78.

31. Robert S, House JS. SES differentials in health by age and alternative indicators of SES. J Aging Health. 1996;8(3):359-88.

32. Jensen MD, Ryan DH, Apovian CM, Ard JD, Comuzzie AG, Donato $\mathrm{KA}$, et al. AHA/ACC/TOS guideline for the management of overweight and obesity in adults: a report of the American College of Cardiology/American Heart Association Task Force on Practice Guidelines and The Obesity Society. Circulation. 2013;2013.

33. Campos P, Saguy A, Ernsberger P, Oliver E, Gaesser G. The epidemiology of overweight and obesity: public health crisis or moral panic? Int J Epidemiol. 2006;35(1):55-60.

34. de Vries J. The obesity epidemic: medical and ethical considerations. Sci Eng Ethics. 2007;13(1):55-67.

35. Galobardes B, Smith GD, Lynch JW. Systematic review of the influence of childhood socioeconomic circumstances on risk for cardiovascular disease in adulthood. Ann Epidemiol. 2006;16(2):91-104.

36. Chittleborough C, Baum F, Taylor A, Hiller J. A life-course approach to measuring socioeconomic position in population 
health surveillance systems. J Epidemiol Community Health. 2006;60(11):981-92.

37. Mazzonna F, Havari E. Can we trust older people's statements on their childhood circumstances? Evidence from SHARELIFE. 2011.

38. Hattori A, Sturm R. The obesity epidemic and changes in self-report biases in BMI. Obesity. 2013;21(4):856-60.

39. Clarke P, O'Malley P, Schulenberg J, Johnston L. Midlife health and socioeconomic consequences ofpersistent overweight across early adulthood: findings from a national survey of american adults (1986-2008). Am J Epidemiol. 2010;172(5):540-8.

40. Gortmaker S, Must A, Perrin J, Sobol A, Dietz W. Social and economic consequences of overweight in adolescence and young adulthood. N Engl J Med. 1993;329(14):1008-12.

41. Braveman PA, Cubbin C, Egerter S, Chideya S, Marchi KS, Metzler $\mathrm{M}$, et al. Socioeconomic status in health research: one size does not fit all. JAMA. 2005;294(22):2879-88. 